\title{
TRANSPOSITION OF VENTRICLES AND ARTERIAL STEMS WITH CEREBRAL ABSCESS
}

\author{
By K. L. Stuart, M.D., M.R.C.P.Ed., and H. E. Flint, M.B., B.Chir. \\ From the Departments of Medicine and Anatomy, University College of the West Indies
}

In the heart to be reported here there are congenital anomalies allowing communication between the right-heart and left-heart circulations, a feature of most of the other reported cases of cerebral abscess occurring in association with congenital heart disease. The anatomical features, however, were unique and of particular interest in relation to their method of development.

The great vessels were completely transposed, the aorta taking origin from the ventricle on the right side of the heart, and the pulmonary trunk from that on the left side. In addition, the auriculo-ventricular valve of the ventricle on the right side had two cusps, while that on the left had three. The ventricle on the right had features of a normal left ventricle and that on the left those of a normal right ventricle. The atria, however, were normal in their connections with the ventricles and in their venous openings. There would have been isolated right heart-body and left heart-lung circulations had there not been a large atrial septal defect which provided communication between the circulations. An additional anomaly in the heart was the presence of a single coronary artery which gave, in its course, branches which approximated to the normal coronary supply from right and left arteries.

The occurrence of cerebral abscess as a complication of congenital heart disease receives only cursory mention in the standard textbooks of medicine, and the number of reported cases is also relatively small. It is likely that the paucity of reported cases represents failure of recognition rather than rarity of occurrence, for it is becoming increasingly evident that the incidence is much higher than is at present indicated. Robbins (1945) reported 3 cases from a total of 53 cases of congenital heart disease of all types examined at post-mortem.

Maronde ( 1950 ) found $I I$ in a total of $8 I$ postmortem cases of congenital heart disease that survived beyond the age of two years and showed at the same time a potential shunt between the systemic venous and arterial circulations. These
I I cases represented 10.4 per cent. of 105 fatal instances of brain abscess from all causes, examined in the same series.

These abscesses, which are usually solitary (Hanna, I94I ; Gates et al., I947), are very suitable to surgical treatment; and a number of successfully treated cases have been reported (Smolik et al., 1946; Sweeney and Patton, 1947). Ehni and Crain (1952) reported a patient with Lutembacher's syndrome, who developed two cerebral abscesses in six years, diagnosed and treated successfully on both occasions. It is suggested that this condition should no longer be regarded as a medical curiosity; and the frequency of its occurrence, the relative ease of diagnosis, once it is suspected, and the good results obtainable by prompt surgery should be re-emphasized.

The patient described here had a solitary right parietal lobe abscess, and died three hours after admission before surgery could be attempted.

\section{Case Report}

L L., a nine-year-old Jamaican girl of mainly Chinese extraction, was admitted to hospital in August 1954 Her illness started I4 days before admission, when she first complained of gradually increasing headaches. Vomiting started within 48 hours and continued off and on until her admission to hospital. The day before admission the headache became more severe, her mental state deteriorated, and she became drowsy and confused.

She had been a 'blue baby' since birth, and her physical activity had always been somewhat restricted because of breathlessness on more than moderate exertion. The cyanosis had increased considerably since the onset of her illness.

Physical Examination. On admission, she was acutely ill. Her temperature was $103.5^{\circ} \mathrm{F}$. She was very cyanosed, and her fingers showed a gross ' drum-stick' clubbing. There was marked bulging of the left side of the praecordium which showed a diffuse pulsation. There were no signs of congestive cardiac failure. The apex beat 
could not be palpated with accuracy, but the point of maximum intensity on auscultation was in the fifth left intercostal space $4 \frac{1}{2}$ inches from the midline, and just outside the mid-clavicular line. Her blood pressure was $110 / 70 \mathrm{~mm}$. $\mathrm{Hg}$. Careful auscultation revealed no significant cardiac murmurs, but there was an extremely loud ringing second sound in the pulmonary area.

Her mental state fluctuated between drowsiness and a resistant stupor. Her co-operation could be obtained for short periods only, and then merely to obey simple commands. When aroused she complained of headache and eyeache, indicating chiefly the right eye. A moderate degree of neck rigidity was present. Her fields of vision and visual acuity could not be tested accurately, but she appeared to notice movements better in the left visual half-field than in the right. Her fundi showed a moderate degree of papilloedema. There was ptosis of the right eyelid, and an external strabismus with some apparent weakness of conjugate deviation of the eyes to the left. The right pupil was larger than the left. Both reacted to light directly and consensually, but sluggishly on the right. The corneal reflex was diminished on the right and absent on the left. Some weakness of the left lower face was noted. There was a spastic weakness of the limbs, more marked on the left and with almost complete paralysis of left arm movements. Sensation to light touch could not be tested, but appreciation of pain sensation appeared normal. The reflexes in both upper limbs were normal, but markedly increased in the lower limbs, especially on the left. There was sustained ankle clonus on the left with a fr:w unsustained beats on the right. The plantar $r$ eflexes were both extensor.

Laboratory Findings. The following laboratory results were obtained on admission. Blood examination: Haemoglobin, 2 r.o g. per cent.; packed cell volume, 62.0 per cent.; white cell count, 16,700 per c.m,1. neutrophils 95 per cent., lymphocytes 3 per cent., smear cells 2 per cent. Two blood cultures were negative. Cerebro-spinal fluid: pressure $300 \mathrm{~mm}$. of water; white cell count, 619 per c.ml. (100 per cent. polymorphs); protein, $200 \mathrm{mg}$. per $100 \mathrm{ml}$; sugar, $45 \mathrm{mg}$. per I $00 \mathrm{ml}$.; no organisms were seen on direct smear; and aerobic and anaerobic cultures were negative.

$\mathrm{X}$-ray chest showed an ill-defined aortic knuckle, with enlarged pulmonary vessels and increased peripheral vascular markings (Fig. I). The appearances suggested congenital heart disease, probably transposition of the great vessels.

The electrocardiogram showed marked right ventricular hypertrophy (Fig. 2).

Diagnosis. A diagnosis of cyanotic congenital heart disease with a rapidly expanding intra-

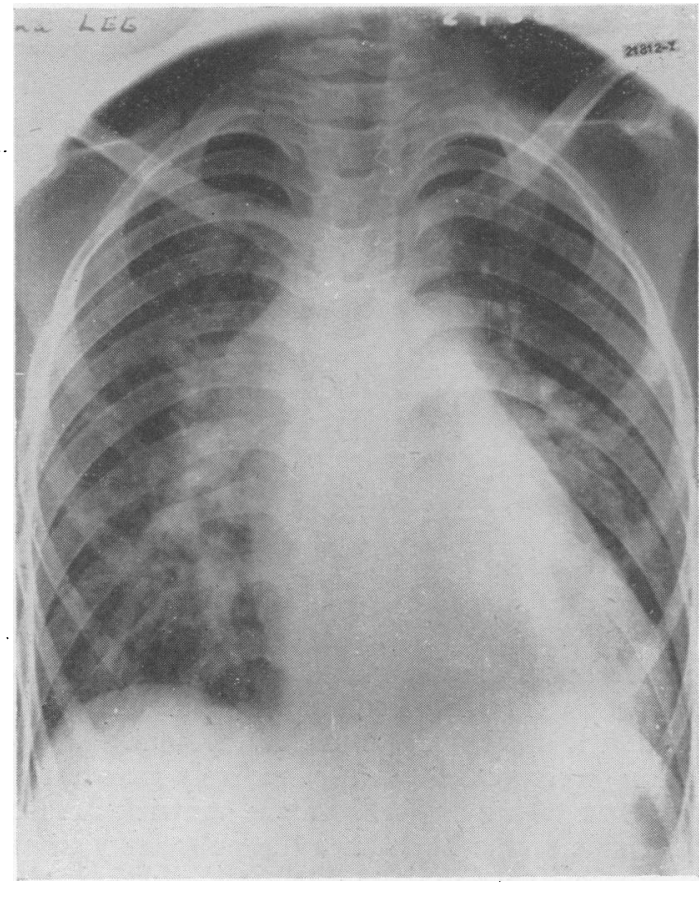

FIG. I.-X-ray of chest showing ill-defined aortic knuckle, enlarged pulmonary vessels and increaseg peripheral vascular markings.

cranial lesion, probably cerebral abscess, was made. The enlargement of the pulmonary vessels with increased peripheral vascular markings, the absence of a significant murmur, and the very loud pulmonary second sound were against a diagnosis of the tetralogy of Fallot. Complete transposition of the great vessels with a shunt between the right and left sides of the heart, probably through an atrial septal defect, seemed a reasonable interpretation of the findings. The other anomalies were not suspected.

\section{Post-mortem Examination}

The only significant observations pertained to the brain and heart. There was no transposition of any of the viscera.

The brain weighed $1,300 \mathrm{~g}$. The meminges $\frac{?}{0}$ were not thickened; but there was marked congestion of the vessels with fattening of the gyri. $\mathcal{N}$ There was an abscess approximately $3 \mathrm{~cm}$. in $N$ diameter in the region of the intraparietal sulcus of the right cerebral hemisphere, immediately $\omega$ behind the post-central gyrus (Fig. 3). Approximately 35 c.c. of greyish sanguineous pus were obtained from this abscess.

The paranasal sinuses and middle ear were clear, showing no evidence of infection. The venous sinuses showed nothing remarkable. 

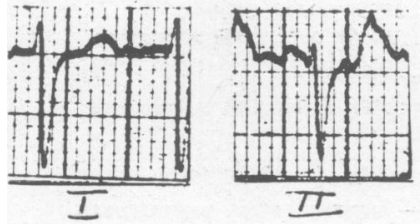

TT
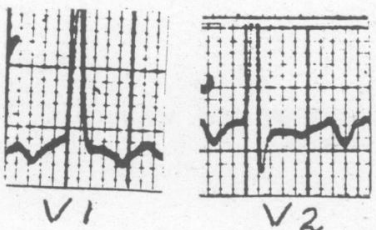
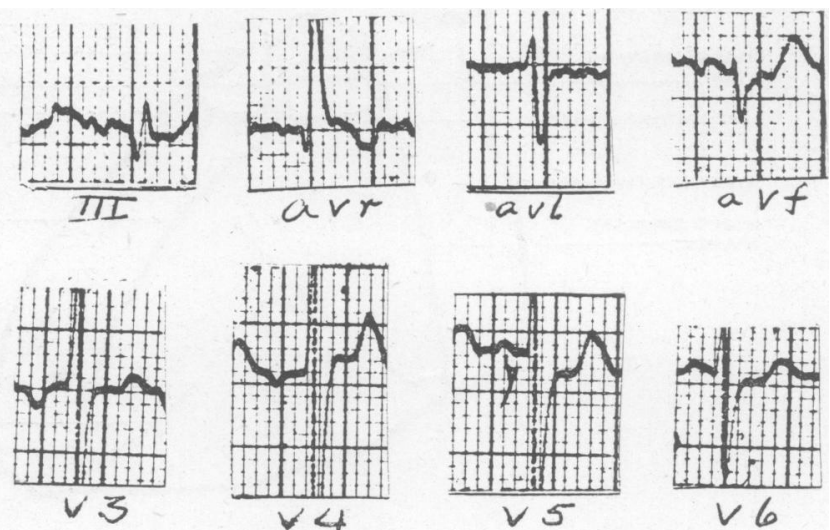

FIG. 2.-Electrocardiogram showing marked right ventricular hypertrophy.

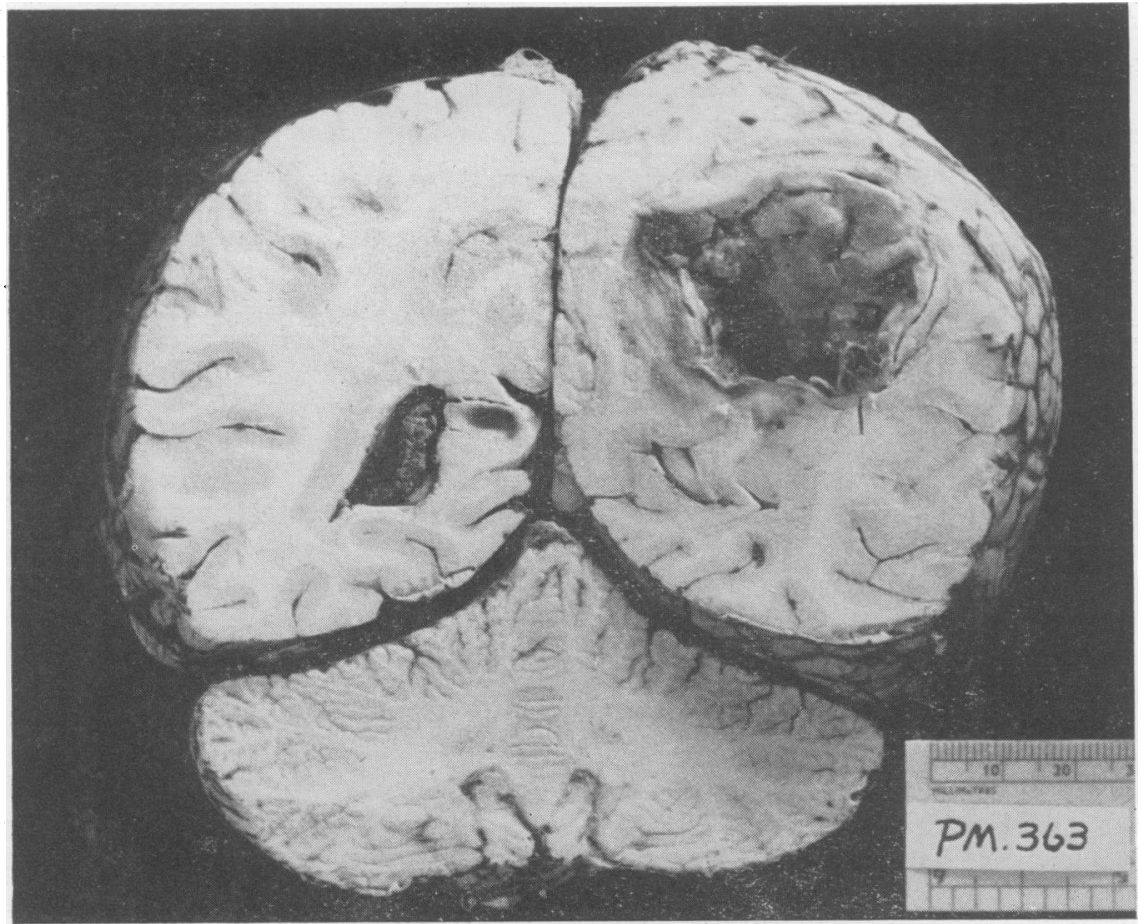

Fig. 3.-Photograph of brain showing right parietal lobe abscess.

Microscopic section of the right cerebral hemisphere showed an abscess with a chronic granulomato:ıs wall. A smear of the pus from the abscess cavity showed a few gram-positive diplococci, gram-positive and gram-negative cocci in chains. There was no growth under aerobic and anaerobic conditions. A blood culture from the cavity of the right ventricle was positive for streptococcus faecalis.

\section{Description of the Heart}

The heart, which was not weighed, had its normal position in the thorax. Its approximate measurements were $8 \mathrm{~cm}$. from base to apex, $7 \mathrm{~cm}$. transversely at its broadest part, and $7 \mathrm{~cm}$. antero-posteriorly.

Great Vessels. The great vessels were transposed, the aorta taking origin from the ventricle on the right side, the pulmonary trunk from the 


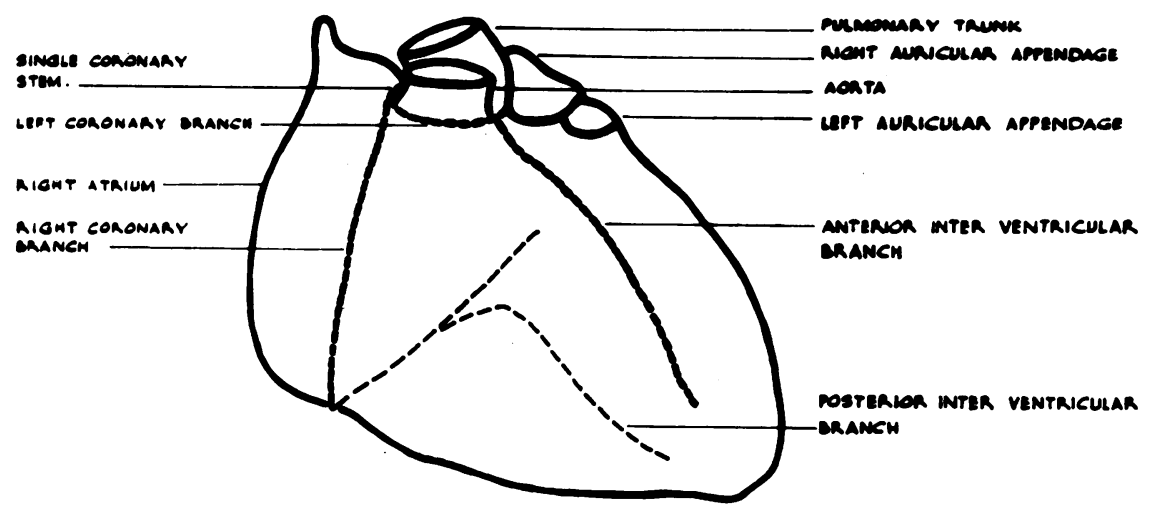

Fig. 4.-Diagram of heart seen from sterno-costal surface.

ventricle on the left side of the heart. The origin of the aorta thus lay anterior and slightly to the right of the pulmonary trunk, and the aorta arched over the pulmonary trunk and right pulmonary artery which lay behind it, and crossed the right bronchus to become the descending thoracic aorta (Figs. 4, 5 and 6). From the arch of the aorta the three great arterial vessels took their normal origins. A patent ductus arteriosus was present, $7 \mathrm{~mm}$. long and of the funnel-shaped type, tapering from an aortic opening $3 \mathrm{~mm}$. in diameter to a narrower pulmonary opening. As the aortic and pulmonary trunks lay in the specimen, the aortic orifice was guarded by two anterior and one posterior cusp, the pulmonary orifice by two posterior and one anterior cusp. A single coronary trunk arose from the sinus of the posterior cusp of the aorta (Figs. 4 and 5).

Ventricles. The ventricle on the right side, from which the aorta arose, showed features of a normal left ventricle and communicated with the right atrium through a two-cusped valve, while the ventricle on the left side showed features of a righıt ventricle and communicated with the left atrium through a valve with three cusps.

The interventricular septum was complete. The cavity of the left-sided ventricle was larger than that of the right, the septum bulging slightly to the right, and the wall of the ventricle on the left side was slightly thicker. The wall of the ventricle on the right side was $7 \mathrm{~mm}$. across with coarse trabeculation extending up to the aortic vestibule. The wall of the ventricle on the left side was $9 \mathrm{~mm}$. across and, on the inner surface, the trabeculae carneae were more numerous, finer, and more delicately interlaced than on the right. A smooth infundibular region lead to the pulmonary orifice. The crista super-ventricularis was not prominent, a shallow ridge passing in the roof of the ventricle between the pulmonary and atrioventricular openings to the septum. A moderator band was not present.

The Atria. The right and left atria were in their normal anatomical relationship. The auricular appendage of the right atrium was in an unusual position lying on the left side of the pulmonary trunk and the upper side of the leftsided ventricle above the left auricular appendage. The two atria were in free communication through a grossly deficient inter-atrial septum. A partiab septum extended as a crescentic fold from the posterior wall and inferiorly; its free crescentico margin was directed forwards, and it was $12 \mathrm{~mm}$. wide from base to free margin in its middle part. In the lower part of the crescent was a large oval deficiency $15 \mathrm{~mm}$. $\times 7 \mathrm{~mm}$., bounded anteriorly by the free edge of the septum which was here well defined and cord-like. Below this was another smaller, fenestrated, deficiency. The crescent represented the septumprimum which was incomplete and had regressed in an abnormal way. The septum secundum was represented by a crescentic ridge superiorly passing on to the posterior wall on the right side of the septum primum. This crescentic ridge crossed the upper part of the septum primum remnant forming the upper sector of the annulus ovalis.

The venae cavae and coronary sinus entered the right atrium, and the four pulmonary veins the left atrium in the usual way.

There was no evidence either in the gross or microscopically of rheumatic fever or subacute bacterial endocarditis.

The Coronary Arteries. A single coronary trunk took origin from the sinus of the posterior aortic cusp, and, in its subsequent course, gave branches which approximate to those of the normal coronary supply from right and left arteries. A small pin-hole dimple was present in the sinus of the left anterior cusp, but this 

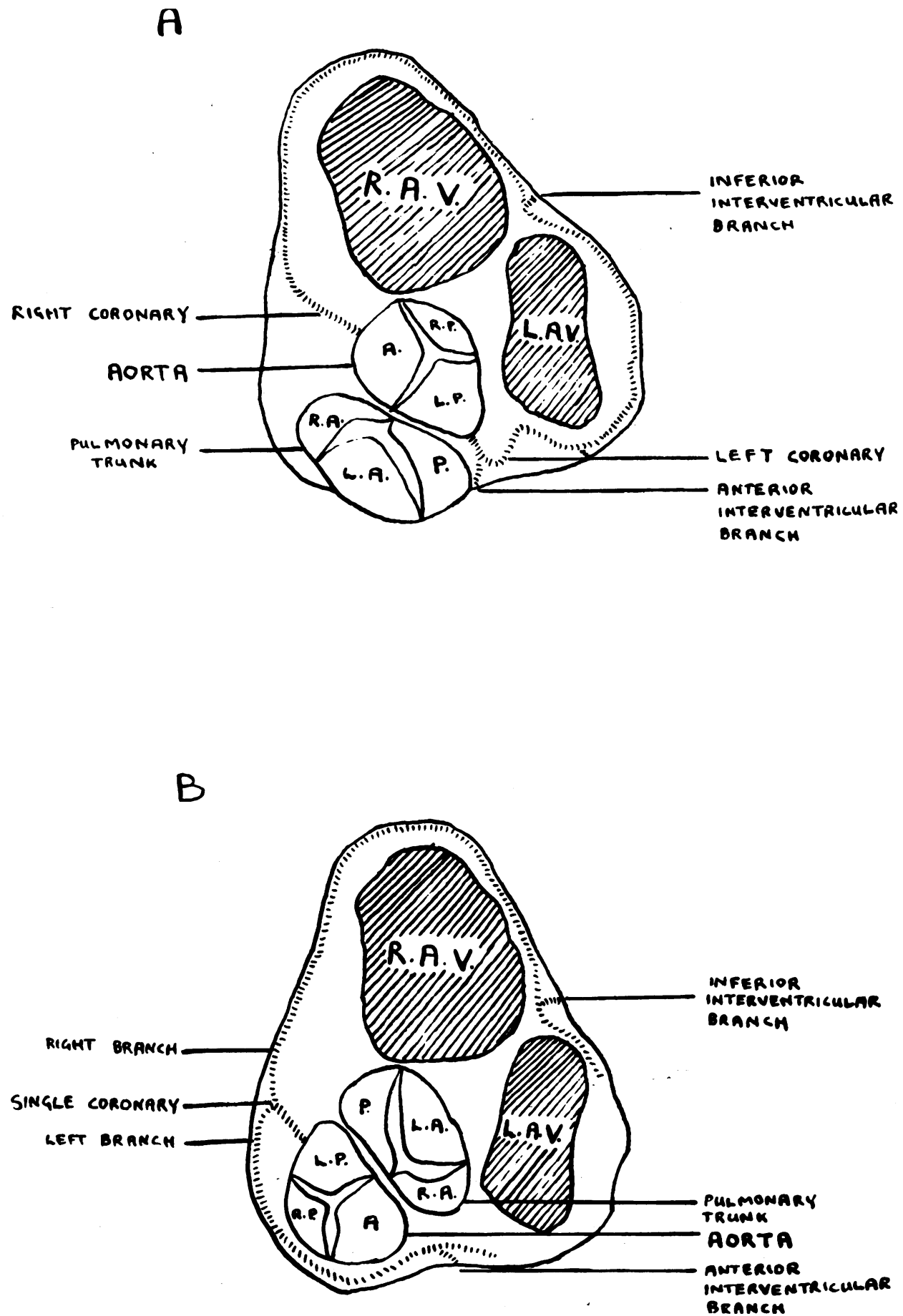

FIG. 5.-Diagram of relationships of great vessels and course of the coronary branches:

A: In the normal heart.

B: In the heart described in the present report. 


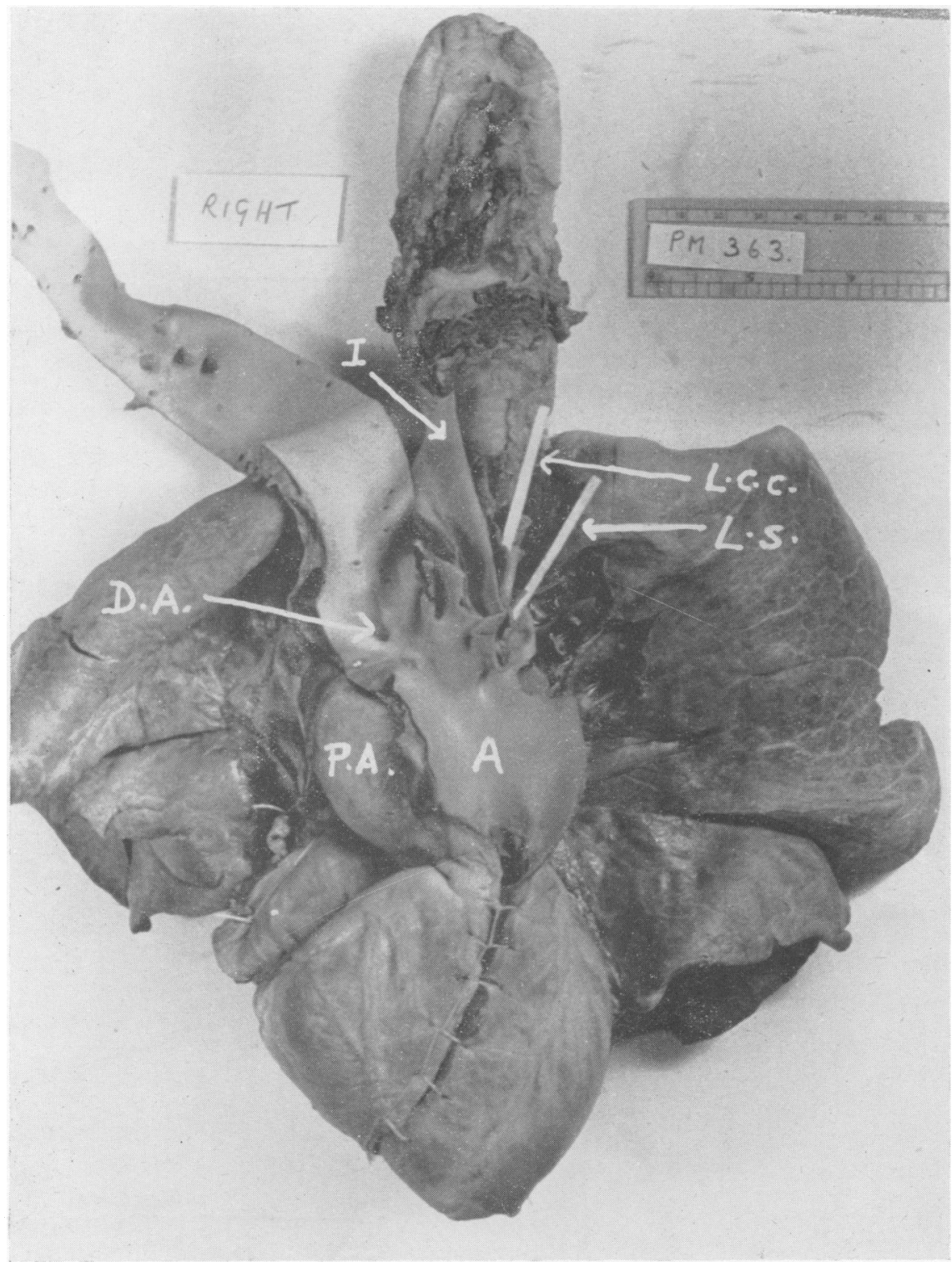

Fig. 6.-Anterior view of heart:

A. = Aorta.

P.A. = Pulmonary artery.

D.A. = Ductus arteriosus.

I. = Innominate artery.

L.C.C. $=$ Left common carotid artery.

L.S. = Left subclavian artery.

had no connection with vessels of the coronary system. The single coronary trunk lay with the aorta on its left and the pulmonary trunk behind and divided, $4 \mathrm{~mm}$. from its origin, into right and left branches (Figs. 4 and 5).
The right branch ran between the base of the pulmonary trunk and the right-sided ventricle to the groove between that ventricle and the right atrium giving branches to the anterior wall of the ventricle. The left branch passed in front of the 
aorta in the groove between the base of the aorta and the right-sided ventricle giving a branch to the surface of its anterior wall.

\section{Discussion}

The Heart. Abnormality in the relationship of the great vessels occurs in Fallot's tetralogy, the Eisenmenger complex and the Taussig-Bing complex, but those cases in which transposition of the great vessels is the main abnormality fall into two groups. In both groups the aorta lies in front of, and slightly to the right of, the pulmonary trunk. In one group the transposition is complete and the aorta arises from the right ventricle, the pulmonary trunk from the left. In the other, rarer group, the transposition is 'corrected' for, despite the abnormal relationship of the two vessels, the aorta arises from the left ventricle, the pulmonary trunk from the right. The venous connections in both groups are normal, and in complete transposition life is only possible if other congenital abnormalities are present allowing communication between the left heart-lung circulation and the right heart-body circulation which would otherwise be entirely separate.

Hanlon and Blalock (1948), in their study of complete transposition and the possibilities of affording relief by surgery, suggest that the chances of survival improve with the number and extent of the additional abnormalities affording communication between the two circulations. In this case the grossly deficient atrial septum and the patent ductus arteriosis, provided ample crosscirulation, and had it not been for the development of the cerebral abscess, a much longer period of survival would have been anticipated. Indeed, there was nothing in her clinical history up to her final illness to suggest any progression of her cardiac disability.

Gould (1953) states that transposition of the great vessels is commonly associated with isolated dextrocardia, and that in some cases the transposition is corrected. The aortic arch usually crosses the left bronchus but may, as in the heart recorded here, cross the right, the descending aorta lying slightly to the left side in both types. In the present case it would seem that the ventricles only have been transposed for the atria are normal in position, apart from the displaced right auricular appendage. The abnormal position of the right auricular appendage in transposition of the great vessels is apparently unusual, although Miskall and Fraser (1948) recorded a case of transposition where the right auricular appendage lay to the left of the great vessels. Ngai (1935) described a heart in which sinitransposition of the right auricle occurred with transposition of the great vessels, a ventricular septal defect, and a left ventricle with no efferent vessel, both aorta and pulmonary trunk arising from the right ventricle. In this heart, as in the present specimen, a single coronary trunk took origin from the aorta on the right side.

The heart described by Walmsley (I93I) provides an interesting comparison, for in his specimen the transposition of the vessels was corrected, the aorta arising from the left-sided ventricle, and the pulmonary trunk from the right-sided ventricle. The left-sided ventricle showed features of a normal right ventricle while the right-sided ventricle resembled a normal left ventricle. There were no septal defects present, the ductus arteriosus was closed, and the atria with their venous connections were normal.

The left-sided atrio-ventricular valve had three cusps, the right-sided atrio-ventricular valve two. A moderator band and a crista supraventricularis were present in the interior of the left-sided ventricle but not in that of the right side, and the trabeculation of the left-sided ventricle was coarse like that of a right ventrisle, while that of the right-sided ventricle was fine like that of a left ventricle. The trabeculation does not show this feature in the heart here presented, being finer in the ventricle on the left side which has no moderator band, but the profuse apical trabeculation is apparent and the infundibular region well demarcated. The atrio-ventricular part of the interventricular septum in our specimen intervened between the right atrium and the left-sided ventricle and not between the left atrium and the right-sided ventricle as it did in the heart described by Walmsley so that, presumably, the posterior part of the interventricular septum met, and fused with, the septum intermedium in the usual manner and was not displaced to the left as Walmsley described for his specimen. Walmsley suggested that the primary anomaly of the heart he described was ' an inversion of the ventricular loop, so that what is here the ventricle of the right side is the descending limb of the loop, and morphologically the left ventricle, and what is the ventricle of the left side is the ascending limb and morphologically the right ventricle' (Walmsley, I93I).

This description would seem to apply equally well to the specimen recorded here for the ventricle on the right side is, apparently, morphologically the left, the ventricle on the left side morphologically the right. Furthermore, Walmsley suggests that inversion of the ventricular loop would produce rotation of the proximal bulbar septum in the reverse of normal so that the infundibulum is included in the ventricle of the left side. He suggests that, in the heart he describes, the distal part of the bulbar septum 


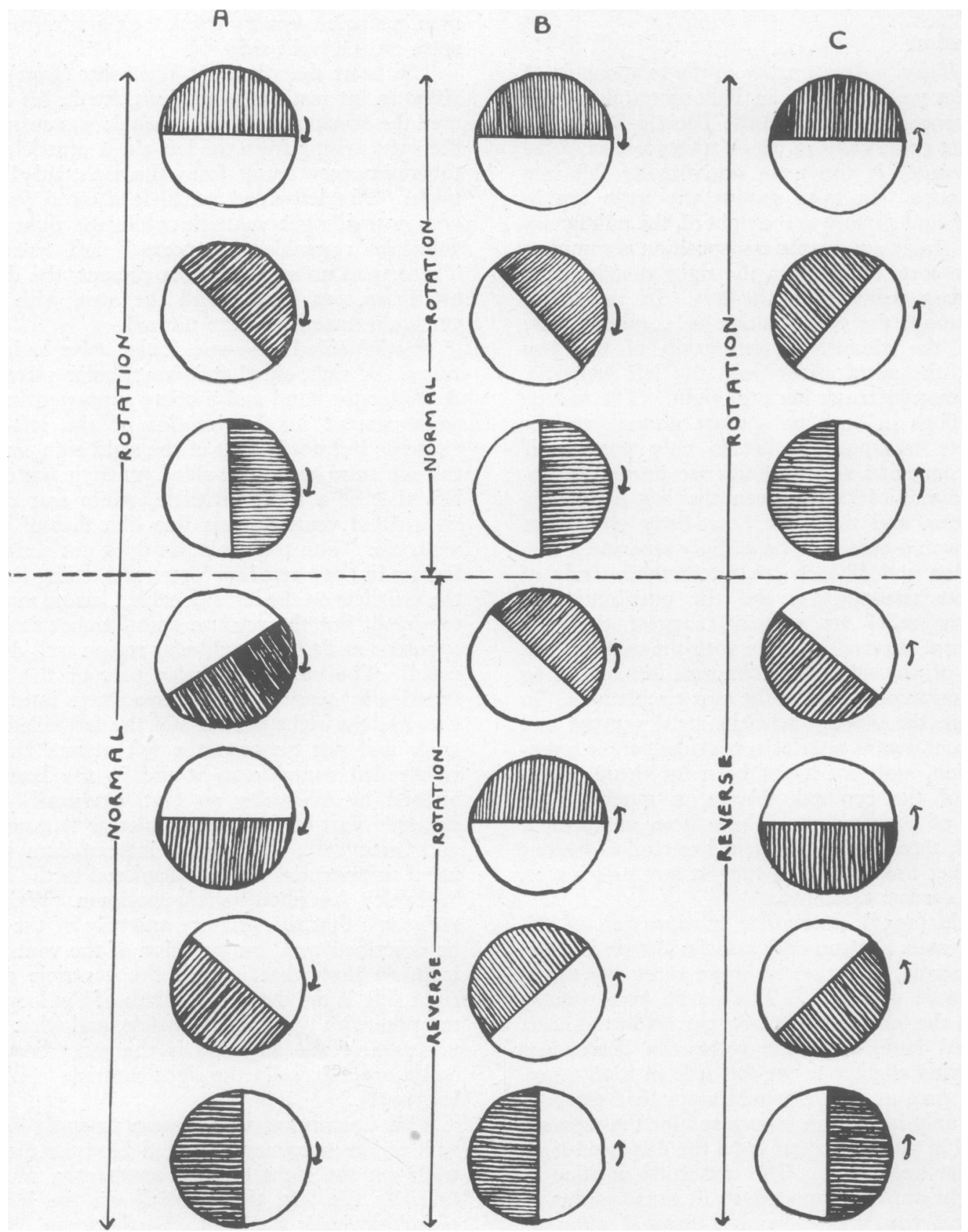

FIG. 7.-The rotation of the arterio-pulmonary and ventricular bulbar septa:

A: In the normal heart.

B: In the heart described by T. Walmsley.

$\mathrm{C}$ : In the heart described in the present report. Based on a diagram published by Walmsley (193 I). 
rotated normally and so, in spite of the inversion of the bulbar loop, a corrected transposition of the great vessels resulted, the aorta originating in the left-sided ventricle.

In the heart here described it is suggested that the reverse rotation of the proximal septum described by Walmsley continued in the distal septum also producing complete transposition (Fig. 7).

The occurrence of a single coronary trunk, while not common, has been reported several times and these cases have been fully reviewed and classified by Krumbhar and Ehrich (1935) and Roberts and Loube (1947). Both reviews refer to Hyrtl's criterion for a single coronary artery which stipulates that the single vessel must supply the entire heart without conspicuous anomalous branches, the anlage of the second coronary artery being completely absent in contradistinction to an anomalous joint origin for the two coronary anlages, or an origin of the one from the other. However, Roberts and Loube suggest that the identification of cases of single coronary artery should be determined by the origin of the coronary arterial circulation from one trunk rather than by the true congenital absence of one coronary artery. White and Edwards (1948) examined the coronary system of 600 hearts, which were primarily the subject of another study, and found three anomalous patterns. In one heart a single coronary stem was present, in two others the left circumflex artery arose as a branch of the right coronary while the anterior descending interventricular artery arose independently from the left aortic sinus, and in a further heart both coronary arteries arose from the left aortic sinus. The single coronary trunk of the heart reported here was probably formed by displacement of the anlage of the missing coronary, for its left and right main branches are distributed in a pattern similar to the distribution of normal left and right coronary arteries. This persisting coronary trunk was on the right of the aorta in the specimen, and represents a persistent left coronary artery of a normally disposed aorta, and the passage of its left branch in front of the aorta follows from this.

Cerebral Abscess. The presence of fever, an elevated white cell count, and pleocytosis of the cerebro-spinal fluid with signs of focal brain disease in a patient with cyanotic congenital heart disease made the diagnosis in this case comparatively easy.

It should be realized, however, that this classical picture is frequently absent; and it has been pointed out that it is precisely in the absence of these obvious findings that the best results may be obtained from surgical intervention (Gluck et al., 1952). There is usually no demonstrable source of infection, and the temperature and white cell count may remain normal until late. The cerebro-spinal fluid also may remain unchanged until rupture of the abscess into the cerebral ventricular system or subarachnoid space has occurred. In a patient with congenital heart disease, therefore, minimal findings, such as persistent and unexplained headaches, drowsiness, slight neck rigidity, and equivocal central nervous system signs should be very critically assessed; and the patient should be carefully observed with this diagnosis in mind, even if the laboratory findings are negative. It is likely that in many cases the diagnosis has been missed because it had not been considered; and in many others dismissed in the early stages because of lack of laboratory confirmation. Once the diagnosis is suspected cranial air studies and electro-encephalography may be useful aids in the early localization of the lesion. Even when the diagnosis has been considered, the distinction from subacute bacterial endocarditis with infected embolization of the brain may yet be difficult.

The precise pathogenesis of brain abscesses occurring in patients with septal defects of the heart is unknown. The time-honoured assumption that they are due to paradoxic emboli provides a reasonable mechanical explanation; and it is feasible that small septic or aseptic emboli may be shunted from the systemic venous to the systemic arterial circulation in patients with this type of heart disease. Maronde (1950) suggests that the pulmonary capillaries act as a bacterial barrier which can be by-passed in the presence of septal defects in the heart. A serious objection to this hypothesis, however, is the absence in our case, as in most reported cases, of a demonstrable source of emboli.

It has been suggested that brain damage precedes the development of an abscess (Hanna, I94I ; Robbins, I945), and there is some postmortem evidence in favour of this (Gluck et al., 1952). The mechanism of production of this antecedent damage, however, is at present obscure; but it seems possible that the slowing of the blood secondary to polycythaemia and increased viscosity may be an important contributory factor in cerebral thrombus formation. The frequency with which a brain abscess follows a suppurative process in the lungs suggests the lungs as an alternative source of emboli; and Rich (1948) has drawn attention to the frequency with which widespread and progressive thrombosis of the pulmonary vessels occurs in congenital heart disease.

\section{Summary}

A case of transposition of the ventricles and 
arterial stems complicated by cerebral abscess has been described. The right ventricle, which had morphological features of a normal left ventricle and was guarded by a bicuspid valve, gave origin to the aorta. The left ventricle resembled a normal right ventricle, was guarded by a tricuspid valve and gave origin to the pulmonary trunk. There was a large atrial septal defect, and a patent ductus arteriosus. The coronary supply was from a single vessel. The anatomical significance and development of these findings are suggested.

The clinical features and aetiology of cerebral abscess in congenital heart disease are discussed. The good results obtainable by prompt surgery are stressed. It is suggested that the development of even minor signs of focal brain damage in such a patient should arouse suspicions of the diagnosis.

\section{BIBLIOGRAPHY}

EHNI, G., and CRAIN, E. L. (1952), F.A.M.A., 150, 1298.

GATES, E. M., RODGERS, H. M., and EDWARDS, E. (1947), Proc. Staff'Meet. Mayo Clinic, 22, 401.

GLUCK, R., HALL, J. W., and STEVENSON, L. D. (1952), Paediatrics, 9, 192.

GOULD, S. D. (1953), ' Pathology of the Heart,' Charles Th omas, Springfield, Illinois.

HANLON, G. R., and BLALOCK, A. (1948), Ann. Surg., 127, 385.

HANNA, R. (1941), Amer. F. Dis. Child., 62, 555.

KRUMBHAAR, E. B., and EHRICH, W. E. (1938), Amer. $\mathcal{F}$ med. Sci., 196, 407.

MARONDE, R. F. (1950), Ann. Int. Med., 33, 602.

MISKALL, E. W., and FRASER, J. A. (1948), Ohio State med. F. 44, 709 .

NGAI, S. K. (1935), Amer. F. Path., II, 309.

RICH, A. R. (1948), Bull. Fohns Hopk. Hosp., 82, 389.

ROBBINS, S. L. (1945), Arch. Int. Med., 75, 279.

ROBERTS, J. T., and LOUBE, S. D. (1947), Amer. Heart $\mathcal{F}$. $34,188$.

SMOLIK, E. A., BLATTNER, R. J., and HEYS, F. M. (1946), F.A.M.A., 130, 145 .

SWEENEY, D. B., and PATTON, W. B. (1950), Southern med. f., 43, 799.

WALMSLEY, T. (1931), F. Anat., $65,528$.

WHITE, N. K., and EDWARDS, J. E. (1948), Arch. Path., 45, 766

\section{RUTHIN CASTLE, NORTH WALES}

A Clinic for the diagnosis and treatment of Internal Diseases (except Mental or Infectious Diseases). The Clinic is provided with a staff of doctors, technicians and nurses.

The surroundings are beautiful. The climate is mild. There is central heating throughout. The annual rainfall is $\mathbf{3 0 . 5}$ inches, that is, less than the average for England.

The Fees are inclusive and vary according to the room occupied.

For particulars apply to THE SECRETARY, Ruthin Castle, North Wales.

Telegrams: Caotio, Ruthin.

Telophene: Ruchin 66

Continued from page 120-Fack Colover, M.D., M.R.C.P. the capacity to produce a type of autosensitization (Lawrence, 1956) which manifests itself under experimental conditions as a meningo-encephalomyelitis with demyelination, having some quite marked resemblance histologically to some of the human demyelinating diseases.

\section{Acknowledgments}

I would like to thank Mr. P. J. Fiske for the microphotography and Mr. J. Dorling for technical assistance. I am very indebted to Dr. L. E. Glynn of the Department of Pathology at the Canadian Red Cross Memorial Hospital, Taplow, for assistance and advice.

\section{BIBLIOGRAPHY}

BARNES, J. M., and DENZ, F. A. (1953), Ұ. Path Bact., 65, 597. BRAIN, W. R., and GREENFIELD; J. G. (1950), Brain, 73, 291. CHRISTIE, G. S., JUDAH, J. D., and REES, K. R. (1953), Proc. roy. Soc. B., I4I, 523.

COLOVER, J. (1954), Brain, 77, 435.

COLOVER, J., and CONSDEN, R. (1955), Excerpta med. (Amst.), Sect. VIII, 8, 808 .

COLOVER, J., and CONSDEN, R. (1956a), Nature, 177, 749.
COLOVER, J., and CONSDEN, R. (1956b), Proc. and Internat. Cong. of Neuropathology. In press.

COLOVER, J. (1956d), Proc. roy. Soc. Med., 49, 154.

CUMINGS, J. N. (1953), Brain, 76, 55 r.

DAWSON, J. R. (1934), Arch. Neurol. Psychiat. (Chicago), 3I, 685

FREUND, J., and MACDERMOTT, K. (1942), Proc. Soc. exp. Biol. (N.Y.), 49, 548 .

GREENFIELD, J. G. (1933), F. Neurol. Psychopath., 13, 289.

HURST, E. W. (1942), Austral. F. exp. Biol. med. Sci., 20, 297.

HURST, E. W. (1944), Brain, 67, 103.

KABAT, E. A., WOLF, A., and BEZER, A. E. (1946), Science, 104, 362 .

KIES, M. W., ROBOZ, E., and ALVORD, E. C. (1956), Fed. Proc.., 15, 288.

KRABBE, K. (1916), Brain, 39, 74.

LAWRENCE, H.S. (1956), Amer. F. Med., $20,428$.

MAGEE, P. N., STONER, M. B., and BARNES, J. M. (1955), Excerpta med. (Amst.), Sect. VIIII, 8, 859.

MORGAN, I. M. (1946), F. Bact., 5I, 614.

NORMAN, R. M. (I947), Brain, 70, 234 .

OLITSKY, P. K., and TAL, C. (1952), Proc. Soc. exp. Biol., 79, 50. RIVERS, T. M., SPRUNT, D. H., and BERRY, G. P. (1933), $\mathcal{f}$. exp. Med., 58, 39.

RIVERS, T. M., and SCHWENTKER, F. F. (1935), ibid., 61, 689. RUSSELL, D. S. (1955), Brain, 78, 369.

STRICH. S. J. (1955), Excerpta med. (Amst.), Sect. VIII, 8, 850. vaN BOGAERT, L. (1945), f. Neurol. Psychiat., 8, 101.

WOLF, A., KABAT, E. A., and BEZER, A. E. (1947), f. Neuropath., 6, 333. 